\title{
Eficiência nutricional na produção de mudas de maracujazeiro azedo em função das concentrações de fósforo em solução nutritiva
}

Nutritional efficiency in the passion fruits seedling production as a result of the phosphorus concentrations in nutritive solution

Eficiencia nutricional en la producción de plántulas de maracuyá como resultado de las concentraciones de fósforo en solución nutritiva

Recebido: 17/03/2021 | Revisado: 23/03/2021 | Aceito: 25/03/2021 | Publicado: 02/04/2021

João Vítor Garcia Silva

ORCID: https://orcid.org/0000-0002-4543-1950 Universidade Federal do Espírito Santo, Brasil E-mail: jaogarciaa@gmail.com

Lana Lirio Longue

ORCID: https://orcid.org/0000-0002-5308-3327

Universidade Federal do Espírito Santo, Brasil

E-mail: lanalongue@hotmail.com

Adriele dos Santos Jardim

ORCID: https://orcid.org/0000-0003-1568-1091

Universidade Federal do Espírito Santo, Brasil E-mail: dricajardim23@hotmail.com

Ana Paula Braido Pinheiro

ORCID: https://orcid.org/0000-0001-9483-1806

Universidade Federal do Espírito Santo, Brasil E-mail: anabraidop@gmail.com

Rayane Rosa

ORCID: https://orcid.org/0000-0002-2015-8898

Universidade Federal do Espírito Santo, Brasil

E-mail: rayane_.rosa@hotmail.com

André Lucas Reboli Pagoto

ORCID: https://orcid.org/0000-0002-8166-9077

Universidade Federal do Espírito Santo, Brasil

E-mail: andrelucasrebolipagoto@ gmail.com

André Luiz Ribeiro Azeredo

ORCID: https://orcid.org/0000-0003-4729-6155

Universidade Federal do Espírito Santo, Brasil

E-mail: alr.azeredo@gmail.com

Sara Dousseau Arantes

ORCID: https://orcid.org/0000-0001-6202-4153

Instituto Capixaba de Pesquisa Assistência Técnica e Extensão Rural, Brasil

E-mail: sara.arantes@incaper.es.gov.br

Adriano Alves Fernandes

ORCID: https://orcid.org/0000-0002-5016-0745

Universidade Federal do Espírito Santo, Brasil

E-mail: afernandesufes@gmail.com

\begin{abstract}
Resumo
Objetiva-se avaliar a produção de mudas de maracujazeiro azedo propagadas por sementes em cultivo hidropônico e associadas a eficiência do uso de fósforo. O delineamento experimental utilizado foi em blocos casualizados com cinco repetições. Os tratamentos foram constituídos pelas concentrações de fósforo de 0,032;0,125;0,500 e 1,000 mmol. $\mathrm{L}^{-1}$. Cada parcela foi composta por 5 plantas dispostas nos perfis de cultivo. As características analisadas foram altura da planta, diâmetro do caule, número de folhas, massa fresca de parte aérea, massa fresca de raiz, massa seca da parte aérea, massa seca das raízes, volume de raiz, área foliar, índice de qualidade de Dickson (IQD) e análise química da parte aérea e raízes para os calculos das eficiências de absorção, translocação e utilização do fósforo. Os dados foram submetidos à análise de variância pelo teste $\mathrm{F}(\mathrm{p}<0,05)$ e análise de regressão, utilizando o software estatístico R. A análise dos dados permitiu concluir que a produção de mudas de maracujá azedo por sementes pode ser realizada como o uso de 0,784 mmol. $\mathrm{L}^{-1}$ de $\mathrm{P}$ na solução nutritiva, permitindo alcançar eficiências relativas de absorção e translocação do nutriente de $98,17 \%$ e $95,65 \%$, respectivamente. O uso dessa concentração proporciona economia de cerca de $22 \%$ do nutriente em relação ao valor original da concentração utilizada na solução nutritiva.
\end{abstract}

Palavras-chave: Passiflora edulis Sims; Qualidade de muda; Rochas fosfáticas; Hidroponia. 


\begin{abstract}
The objective of the work was to evaluate the production of sour passion fruit seedlings propagated by seeds in hydroponic cultivation and associateds with phosphorus use efficiency. The experiment was carried out in a greenhouse at the experimental farm of the Centro Universitário Norte do Espírito Santo. The experimental design used was in randomized blocks with five replications. The treatments consisted of phosphorus concentrations of $0.032 ; 0.125 ; 0.500$ and 1,000 mmol. $\mathrm{L}^{-1}$. Each plot was composed of 5 plants arranged in the cultivation pipes. The characteristics analyzed were plant height, stem diameter, number of leaves, fresh shoot weight, fresh root weight, dry shoot weight, dry root weight, root volume, leaf area, quality index of Dickson (IQD) and chemical analysis of the aerial part and roots to calculate the absorption, translocation and use of phosphorus efficiency. The data were subjected to analysis of variance by the $F$ test $(p<0.05)$ and regression analysis, using the statistical software $R$. Data analysis concluded that the production of sour passion fruit from seeds can be accomplished as the use of 0.784 mmol. $\mathrm{L}^{-1}$ phosphorus in the nutrient solution, allowing to achieve relative efficiencies of absorption and translocation of nutrient $98.17 \%$ and $95.65 \%$, respectively. The use of this concentration provides savings of about $22 \%$ of the nutrient in relation to the original concentration value of the used nutrient solution.
\end{abstract}

Keywords: Passiflora edulis Sims; Seedling quality; Phosphate rocks; Soilless culture.

\title{
Resumen
}

El objetivo es evaluar la producción de plántulas de maracuyá ácidas propagadas por semillas en cultivo hidropónico y asociadas a la eficiencia del uso de fósforo. El diseño experimental utilizado fue en bloques al azar con cinco repeticiones. Los tratamientos consistieron en concentraciones de fósforo de $0.032 ; 0,125 ; 0.500$ y $1,000 \mathrm{mmol}^{-1} \mathrm{~L}^{-1}$. Cada parcela estaba compuesta por 5 plantas dispuestas en los perfiles de cultivo. Las características analizadas fueron altura de planta, diámetro de tallo, número de hojas, materia fresca de parte aérea, materia fresca de raíz, materia seca de parte aérea, materia seca de raíz, volumen de raíz, área foliar, índice de calidad de Dickson (IQD) y análisis químico de la parte aérea y raíces para calcular la eficiencia de absorción, translocación y uso de fósforo. Los datos fueron sometidos a análisis de varianza mediante la prueba $\mathrm{F}$ ( p <0.05) y análisis de regresión, utilizando el software estadístico R. El análisis de datos permitió concluir que la producción de plántulas de maracuyá ácida por semillas se puede realizar como el uso de $0,784 \mathrm{mmol} . \mathrm{L}^{-1}$ de $\mathrm{P}$ en la solución nutritiva, lo que permite alcanzar eficiencias relativas de absorción y translocación de nutrientes de 98,17\% y 95,65\%, respectivamente. El uso de esta concentración proporciona ahorros de aproximadamente un $22 \%$ del nutriente en relación con el valor original de la concentración utilizada en la solución nutritiva.

Palabras clave: Passiflora edulis Sims; Calidad de plântula; Rocas de fosfato; Hidroponia.

\section{Introdução}

A família Passifloraceae é amplamente distribuída pela América Tropical, sendo a espécie Passiflora edulis Sims f. flavicarpa Degener, também conhecida como maracujazeiro azedo, nativa do Brasil, que é o maior produtor comercial e consumidor dos frutos da cultura (Aguiar, Gonçalves, Paterniani, Tucci, \& Castro, 2014; Faleiro \& Junqueira, 2016). No Brasil, é cultivada em 43.384 hectares, sendo esses responsáveis por uma produção de 604.271 toneladas segundo o Instituto Brasileiro de Geografia e Estatística - IBGE (2020).

A produção de mudas de qualidade é um critério que se faz essencial frente ao mercado, pois o torna mais competitivo e melhora o sistema de cultivo. A necessidade de buscar melhor qualidade de muda está associada ao uso de novas tecnologias, que permitem em alguns casos acelerar o processo de formação. Técnicas como manejo correto da irrigação, instalações adequadas para a produção e uma adubação equilibrada ajudam a manter a qualidade das mudas, evitando possíveis contaminações com pragas e doenças (Gontijo, 2017). Por ser uma etapa fundamental no sistema de produção, torna-se necessário o conhecimento do tipo de substrato para o desenvolvimento, exigência nutricional e adubação das plantas, pois em geral, necessitam de quantidades específicas de nutrientes e na forma adequada (Brasil, Viégas, Silva, \& Gato, 1999).

O fósforo é um macronutriente importante para o desenvolvimento das mudas, pois além da função de armazenamento de energia é componente dos lipídeos e acelera a formação de raízes. Esse elemento tem origem no mineral apatita, podendo ser encontrado nas reservas brasileiras de rochas fosfáticas. Por ser um nutriente finito e insubstituível, medidas devem ser adotadas para aumentar a vida útil das reservas, como o manejo e correção da acidez do solo, aumentar a eficiência das adubações fosfatadas devido à forte interação com o solo e buscar, através da genética e melhoramento, plantas mais eficientes na captura e aproveitamento do fósforo (Malavolta, 2006). 
No Brasil, o fósforo é o macronutriente aplicado em maiores quantidades, porém é o menos exigido pelas plantas, fato explicado pela baixa disponibilidade do mineral nos solos brasileiros e a forte interação que ele apresenta quando adsorvido pelos coloides, formando compostos de baixa solubilidade (Furtini, Vale, Resende, Guilherme, \& Guedes, 2001). No cultivo hidropônico, como não se utiliza solo, não há ocorrência desse processo e todo o fósforo da solução está disponível para a absorção, possibilitando um melhor aproveitamento do nutriente (Primavesi \& Malavolta, 1980).

As vantagens do cultivo hidropônico são várias, como melhor controle sobre a composição dos nutrientes fornecidos às plantas, redução do ciclo da cultura e maior produtividade, menor consumo de água e de fertilizantes, entre outras (Santos, Soares, Silva, Silva, \& Montenegro, 2010).

Assim, dentro deste contexto, o presente trabalho teve como objetivo avaliar a produção de mudas de maracujá azedo propagadas por sementes em cultivo hidropônico e associadas a eficiência do uso de fósforo.

\section{Metodologia}

O experimento foi conduzido entre os meses de fevereiro e abril de 2019. A região apresenta latitude de $18^{\circ} 40^{\prime} 32^{\prime \prime S}$, longitude de 39 $51^{\prime} 39^{\prime \prime} \mathrm{W}$ e altitude de $37 \mathrm{~m}$ acima do nível do mar. A classificação climática, segundo Köppen, é tropical úmido do tipo $\mathrm{AW}$ com inverno seco, temperaturas médias de $25^{\circ}$ a $30^{\circ} \mathrm{C}$ no verão e de $19^{\circ}$ a $21^{\circ} \mathrm{C}$ no inverno, com precipitação anual média entre $1000 \mathrm{~mm}$ e $1400 \mathrm{~mm}$. (Alvares, Stape, Sentelhas, Gonçalves, \& Sparovek, 2013).

O delineamento experimental utilizado foi em blocos casualizados com cinco repetições. Os tratamentos foram constituídos pelas concentrações de fósforo de 0,$032 ; 0,125 ; 0,500$ e 1,000 mmol.:-1. Cada parcela foi composta por 5 plantas dispostas nos perfis de cultivo.

Os frutos de maracujazeiro foram selecionados quanto à maturação, fitossanidade, defeitos físicos visíveis e consistência. As sementes foram extraídas manualmente e friccionadas em peneiras de arame para remoção do arilo, seguido de secagem a sombra conforme recomenda Manica et al. (2005). As sementes foram tratadas com fungicida Captan® SC (Adama) a $1 \%$ por 15 minutos e levadas para germinar em mesa de germinação com declividade de $4 \%$ no próprio cultivo protegido. O substrato utilizado foram placas de espuma fenólica com dimensões de 2,5x2,5×3,0 cm por célula. As placas foram lavadas em água deionizada para eliminar compostos ácidos provenientes da fabricação e ajustar o pH à faixa ideal entre 5,5 e 6,5. A semeadura foi realizada em 18 de fevereiro de 2019, adicionando-se 2 sementes por célula com profundidade de $1 \mathrm{~cm}$. Foram avaliadas as sementes e as mudas.

As sementes foram avaliadas 8 dias após a semeadura (DAS), quando observou-se as primeiras plântulas emergidas, permancendo a contagem por mais 9 dias. Considerou-se plântula emergida aquela que apresentou as folhas cotiledonares abertas. A porcentagem de emergência foi calculada diáriamente. $\mathrm{O}$ índice de velocidade de emergência foi calculado de acordo com Maguire (1962):

$$
I V E=\frac{N 1}{D 1}+\frac{N 2}{D 2}+\cdots+\frac{N r}{D r}
$$

Onde: IVE: índice de velocidade de emergência; N: números de plântulas verificadas no dia da contagem; D: números de dias após a semeadura em que foi realizada a contagem.

A irrigação foi realizada com água deionizada até a emergência. Posteriormente, irrigou-se com a solução nutritiva 02 de Martinez e Silva (2012) a 1/2 força iônica. O desbaste foi realizado aos 17 DAS com auxílio de tesoura, deixando uma plântula por célula, sendo essas transferidas para a bancada de cultivo com declividade de $4 \%$ contendo, pelo menos, uma folha completamente expandida.

A solução nutritiva utilizada para produção de mudas foi alterada quando as mudas foram transportadas para as bancadas de cultivo, passando para 1 força iônica (Martinez \& Silva, 2012). A solução com 1 força iônica foi preparada 
contendo os macronutrientes nas concentrações: 13,6; 1,0;7,0;4,48; 2,5 e 2,5 mmol.L $\mathrm{L}^{-1} \mathrm{de} \mathrm{N}, \mathrm{P}, \mathrm{K}, \mathrm{Ca}, \mathrm{Mg}$ e $\mathrm{S}$ respectivamente, e para micronutrientes, as concentrações de 45; 32; 46; 2; 0,9; e 0,2 $\mu$ mol.L.1 para Fe, Mn, B, Zn, Cu e Mo, respectivamente. A concentração de fósforo foi alterada na solução de acordo com os tratamentos. As mudas foram cultivadas utilizando a técnica do fluxo laminar de nutrientes (NFT), que se baseia em um filme de solução nutritiva que circula dentro de canais com declividade determinada, tendo como seus componentes: tanques, bomba hidráulica, misturador e filtro, instalações elétricas, canais para sistemas NFT e tubulações plásticas para distribuição da solução nutritiva (Martinez \& Silva, 2012).

$\mathrm{O}$ pH da solução foi monitorado com peagâmetro portátil e ajustado à faixa de 5,5 a 6,5 sempre que necessário, utilizando-se $\mathrm{HCl}$ ou $\mathrm{NaOH}$ a $1 \mathrm{~N}$. A reposição dos nutrientes foi feita com base na condutividade elétrica, admitindo-se até $20 \%$ de depleção sobre a condutividade inicial da solução nutritiva. Durante o experimento, o consumo de água pelas plantas foi monitorado e a reposição foi realizada, admitindo-se uma redução máxima em torno de $20 \%$ do volume inicial. A temperatura também foi monitorada diariamente no interior da casa de vegetação (Figura 1).

Figura 1. Gráfico de temperatura máxima, média, mínima e de umidade relativa (UR) em função dos dias após a semeadura (DAS).

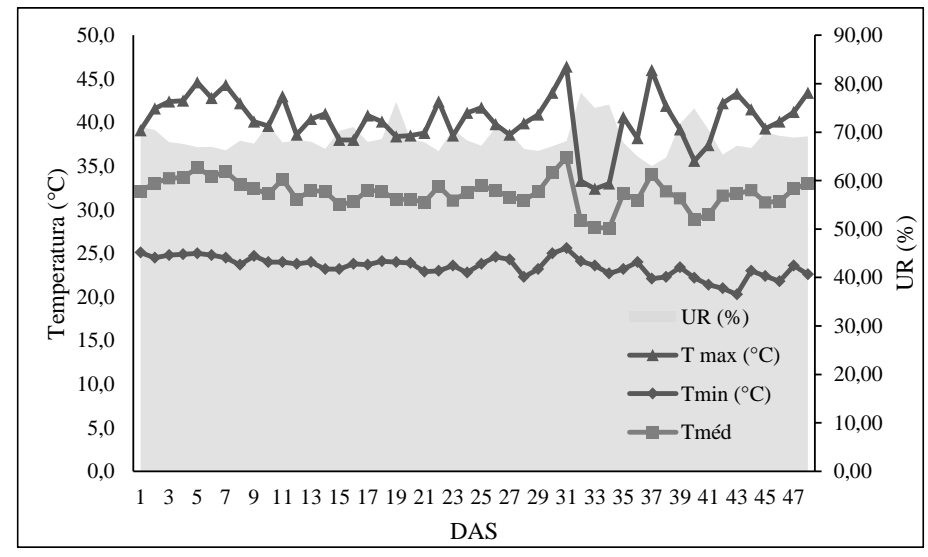

Fonte: Autores.

A análise final foi feita 47 DAS, quando $50 \%$ das plantas apresentaram a primeira folha modificada na forma de gavinha. Foram avaliadas altura da planta (ALT), diâmetro do caule (DC), número de folhas (NF), massa fresca de parte aérea (MFPA), massa fresca de raiz (MFR), massa seca da parte aérea (MSPA), massa seca das raízes (MSR), volume de raiz (VR), área foliar (AF), índice de qualidade de Dickson (IQD) e análise química da parte aérea e raízes.

A altura da planta foi obtida com auxílio de uma régua graduada, medindo do coleto até a extremidade do ramo dominante. O diâmetro do coleto foi determinado com um paquímetro digital (marca INSIZE). As massas foram obtidas por medição direta em balança analítica de precisão com três casas decimais. As massas secas foram determinadas após secagem em estufa a $65^{\circ} \mathrm{C}$ até peso constante, o que ocorreu após o período de 72 horas. O volume de raiz foi feito com auxílio de proveta graduada e calculado pela diferença entre volume inicial e volume final após inserção das raízes. A área foliar foi medida utilizando o equipamento medidor de área foliar Li-Cor modelo L1-3100. A análise química foi determinada de acordo com o Manual de análises químicas de solos, plantas e fertilizantes da Embrapa (Silva et al., 2009).

O índice de qualidade de Dickson (IQD) foi determinado conforme Dickson, Leaf, e Hosner (1960):

$$
\mathrm{IQD}=\frac{\mathrm{MST}}{\frac{\mathrm{H}}{\mathrm{DC}}+\frac{\mathrm{MSPA}}{\mathrm{MSR}}}
$$


Onde: H: altura da planta (cm), DC: Diâmetro de caule (mm), MST: Massa seca total (g), MSPA: Massa seca da parte aérea (g), MSR: Massa seca de raiz (g).

A partir da análise química dos nutrientes, foram efetuados os cálculos referentes à eficiência de absorção, eficiência de translocação e à eficiência de utilização, conforme as equações a seguir:

$$
\text { Eficiência de Absorção }\left(m g g^{1}\right)=\frac{\text { Conteúdo do nutriente na planta }}{\text { Massa seca da raiz }}
$$

(Swiader, Chyan, \& Freiji, 1994).

$$
\text { Eficiência de Translocação }=\frac{\text { Conteúdo do nutriente na parte aérea }}{\text { Conteúdo do mutriente na planta }}
$$

(Li, McKeand, \& Allen, 1991).

$$
\text { Eficiência de Utilização }\left(g^{2} m g^{1}\right)=\frac{(\text { Massa seca total })^{2}}{\text { Conteúdo do nutriente na planta }}
$$

(Siddiqi \& Glass, 1981).

Os dados foram submetidos à análise de variância pelo teste $\mathrm{F}(\mathrm{p}<0,05)$ e aqueles que apresentaram diferença significativa foram submetidos à análise de regressão. Os pontos de máxima e mínima foram definidos pela derivada primária e secundaria da regressão. Todas as análises pertinentes foram realizadas no software estatístico R (R CORE TEAM 2019) com auxílio do pacote 'ExpDes.pt' (Ferreira, Cavalcanti, \& Nogueira, 2017).

\section{Resultados e Discussão}

Nas condições do cultivo protegido, foi observada a emergência de 55,83\% e índice de velocidade de emergência médio (IVEm) de 10,7, sendo o máximo de 16,8 obtido no $13^{\circ}$ dia de avaliação (Figura 2). Em trabalho realizado por Lima, Caldas, e Santos (2006), foi observado para maracujá azedo um IVE de 8,85 com emergência de $95 \%$ em casa de vegetação.

Figura 2. Índice de velocidade de emergência (IVE) em função dos dias após a semeadura (DAS).

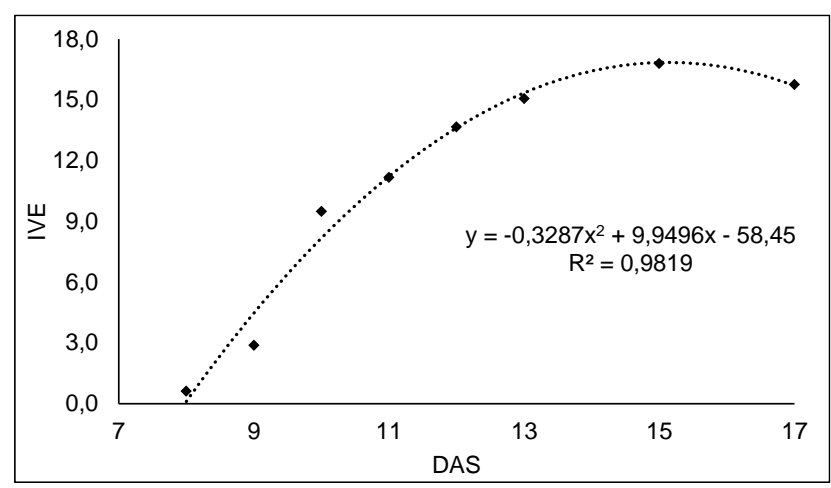

Fonte: Autores.

A germinação baixa é um indicativo de que as sementes podem ter sido comprometidas pelas altas temperaturas observadas no local de cultivo. A máxima média foi acima de $40^{\circ} \mathrm{C}$ nos períodos de germinação e emergência, sendo a média sempre acima de $32^{\circ} \mathrm{C}$ (Figura 1). Conforme recomenda as Regras para Análise de Sementes (Brasil, 2009), a faixa de temperatura ideal para a germinação de Passiflora edulis é de 20 a $30^{\circ} \mathrm{C}$, sendo a temperatura de $25^{\circ} \mathrm{C}$ a ideal para a espécie nas condições testadas em laboratório. 
Houve influência significativa das concentrações de fósforo na altura da planta, diâmetro de caule e número de folhas. Aplicando análise de regressão nos dados de altura da planta foi possível ajustar uma equação quadrática, estimando o ponto de máximo desenvolvimento na concentração próxima de 0,759 mmol.L ${ }^{-1}$, correspondendo a $41,57 \mathrm{~cm}$ (Figura 3).

Figura 3. Altura da planta (ALT) de maracujá azedo, em função das concentrações de fósforo na solução nutritiva, 47 dias após a semeadura.

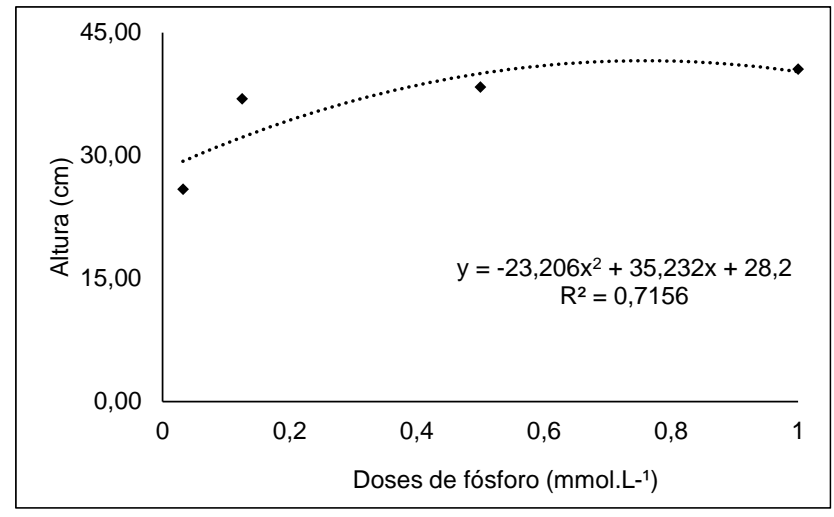

Fonte: Autores.

O fato do fósforo ser constituinte da molécula de ATP, participar de várias reações na planta e atuar no processo de transferência de energia (Taiz \& Zeiger, 2017), explica as maiores alturas na concentração próxima de $0,759 \mathrm{mmol} . \mathrm{L}^{-1}$, mostrando que esse nutriente influencia diretamente no desenvolvimento das mudas de maracujá, sendo que concentrações acima desse ponto de máxima podem ser prejudiciais a essa característica. Normalmente as mudas de maracujá azedo são transplantadas quando atingem o tamanho de 15 a $30 \mathrm{~cm}$ de altura, o que deve ocorrer no intervalo de 40 a 70 dias após a semeadura (Gontijo, 2017). Os resultados observados ultrapassaram a altura máxima descrita na literatura, dentro do tempo esperado, sendo a diferença de 38,57\% no ponto de máxima, mostrando que no cultivo hidropônico o valor da altura das plantas foi superior em praticamente todas as doses, com exceção da $0,032 \mathrm{mmol} \cdot \mathrm{L}^{-1}$.

$\mathrm{Na}$ análise de regressão, aplicada ao diâmetro de caule em função das concentrações de fósforo, constatou-se uma equação do tipo quadrática, sendo o diâmetro máximo de 5,38 mm estimado na dose de 0,709 mmol.L-1 (Figura 4). Negreiros, Álvares, Braga, e Bruckner (2004), trabalhando com mudas de maracujazeiro amarelo em sacos de polietileno, avaliaram a utilização de diferentes substratos e obtiveram o valor médio de diâmetro de caule de 4,25 mm aos 90 dias após o plantio das sementes.

Figura 4. Diâmetro do caule de mudas de maracujá azedo, em função das concentrações de fósforo na solução nutritiva, 47 dias após a semeadura.

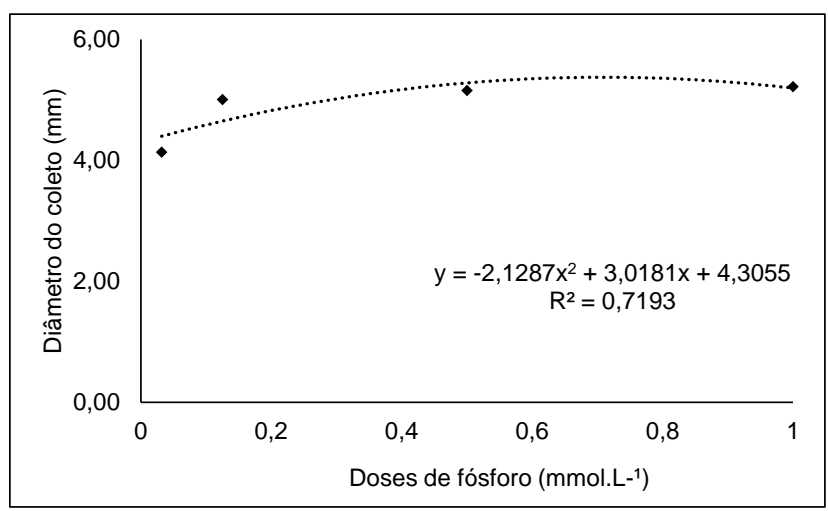

Fonte: Autores. 
A partir da equação de regressão do tipo quadrática, encontrada para o número de folhas, foi possível estimar o número máximo de aproximadamente 19 folhas com a aplicação de 0,794 mmol.L-1 de fósforo na solução nutritiva (Fig. 5). Prado, Vale, e Romualdo (2005) encontraram também efeito quadrático na regressão para número de folhas de maracujá azedo em cultivo protegido em condições de vasos, em função de doses crescente de fósforo. De acordo Nogueira, Roncatto, Ruggiero, Oliveira, e Malheiros (2010), o número de folhas, em condições de campo, é uma característica que na cultura do maracujá pode sofrer variações decorrentes de fatores que não condizem ao crescimento da planta, sendo necessário a avaliação de outro parâmetro, como por exemplo, o número de internódios. No entanto, nesse estudo em cultivo protegido, foi obtido para o número de folhas um coeficiente de variação de 8,92\%, classificado como baixo (Pimentel-Gomes, 2009). Os fatores não inerentes ao crescimento da planta, como doenças e pragas, não foram identificados no decorrer do experimento, $o$ que ocasionou pouca interferência. Assim, observou-se que com esses fatores controlados, refletindo em um baixo coeficiente de variação, o número de folhas pode ser um parâmetro importante na avaliação das mudas.

Figura 5. Número de folhas de mudas de maracujá azedo, em função das concentrações de fósforo na solução nutritiva, 47 dias após a semeadura.

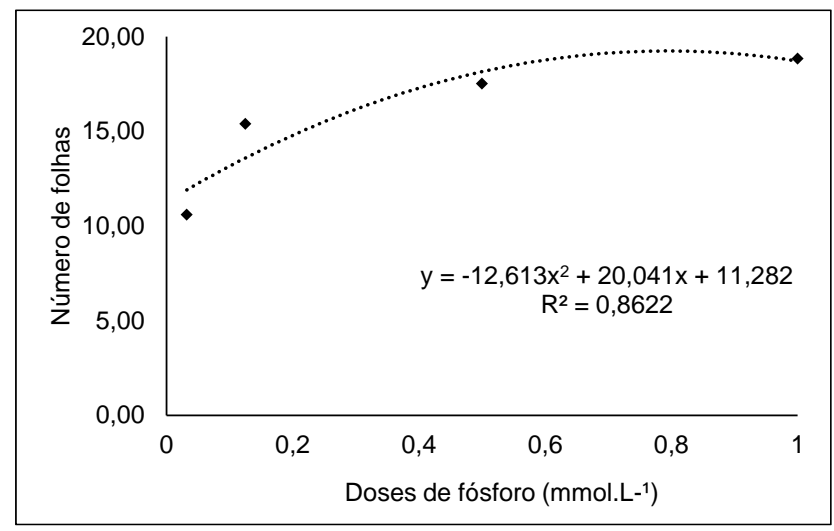

Fonte: Autores.

Efeito quadrático na regressão foi encontrado para os dados de área foliar (Figura 6), estimando-se o valor de 944,34 $\mathrm{cm}^{2}$ como ponto máximo na dose de $0,879 \mathrm{mmol} \cdot \mathrm{L}^{-1}$. A área foliar é um parâmetro biológico importante, pois afeta a fotossíntese, taxa de respiração das culturas e taxa de crescimento (Morgado, Bruckner, Rosado, Assunção, \& Santos, 2013). Maiores valores de área foliar proporcionam maiores áreas fotossintéticas, tendo assim, uma maior produção de fotoassimilados e consequentemente mudas mais vigorosas e de boa qualidade (Santos et al., 2014).

Figura 6. Área foliar de mudas de maracujazeiro, em função das concentrações de fósforo na solução nutritiva, 47 dias após a semeadura.

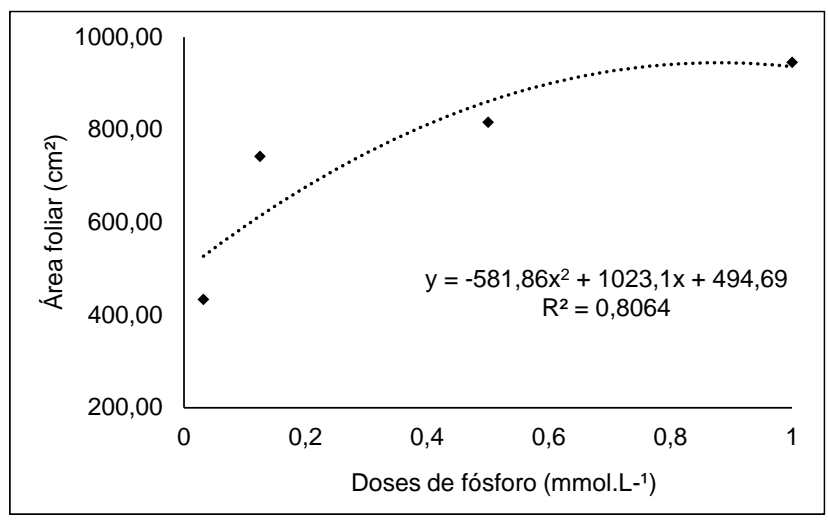

Fonte: Autores. 
A melhor resposta observada para massa fresca da parte aérea foi o ajuste da regressão quadrática (Figura 7). A máxima massa fresca foi estimada em $35,73 \mathrm{~g}$ na dose de $0,854 \mathrm{mmol} \cdot \mathrm{L}^{-1}$. Por se tratar de um nutriente limitante ao desenvolvimento das plantas, a dose mais baixa respondeu com menor massa fresca, menor altura da planta (Figura 3), diâmetro do caule (Figura 4) e número de folhas (Figura 5).

O incremento da massa fresca de raiz aumentou de forma linear em relação ao aumento da concentração de fósforo (Figura 7). Efeito linear para MFR, também foi encontrado por Prado et al., (2005) avaliando o fósforo na produção de mudas de maracujazeiro em casa de vegetação e Silva, Ignacio, e Silva (2017) avaliando mudas de maracujá azedo em diferentes doses de fósforo reativo em condições de campo.

Figura 7. Produção de massa fresca da parte aérea - MFPA (A) e da raiz - MFR (B) em mudas de maracujazeiro, em função das concentrações de fósforo na solução nutritiva, 47 dias após a semeadura.

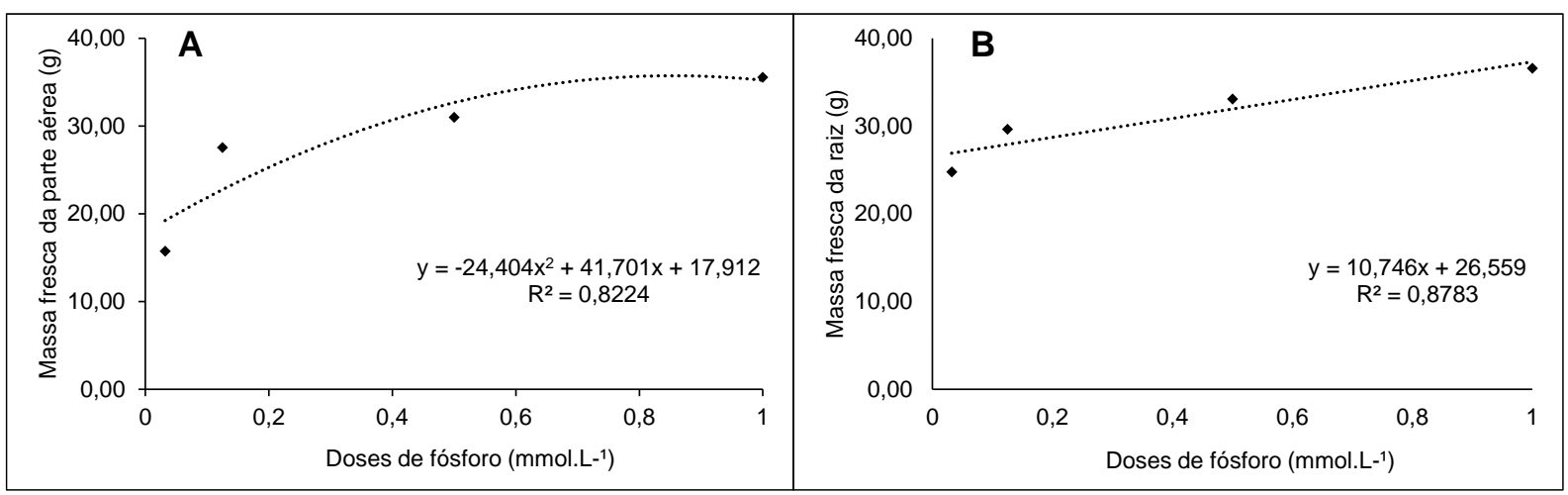

Fonte: Autores.

A máxima produção de massa seca da parte aérea de 6,16g e a máxima produção das raízes de 2,33 g foram estimadas a partir da equação de regressão quadrática, nas doses de $0,924 \mathrm{mmol} \cdot \mathrm{L}^{-1}$ e $0,766 \mathrm{mmol} \cdot \mathrm{L}^{-1}$, respectivamente (Figura 8). Principalmente para as frutíferas, a produção de MSPA é uma das primeiras variáveis a se avaliar na busca de informações sobre uma determinada cultivar (Silva et al., 2017). Em trabalho realizado por Torchelsen (2013), com estacas de maracujazeiros cultivadas em sistema hidropônico do tipo "floating", foi observado o valor de 3,52 g para massa fresca média da parte aérea, enquanto para massa seca média de raiz, variou conforme a cultivar estudada entre $0,56 \mathrm{~g}$ e $0,67 \mathrm{~g}$. Valores mais altos foram encontrados no presente estudo, possivelmente, por se tratarem de mudas seminíferas.

Figura 8. Produção de massa seca da parte aérea - MSPA (A) e da raiz - MSR (B) de mudas de maracujazeiro, em função das concentrações de fósforo na solução nutritiva, 47 dias após a semeadura.

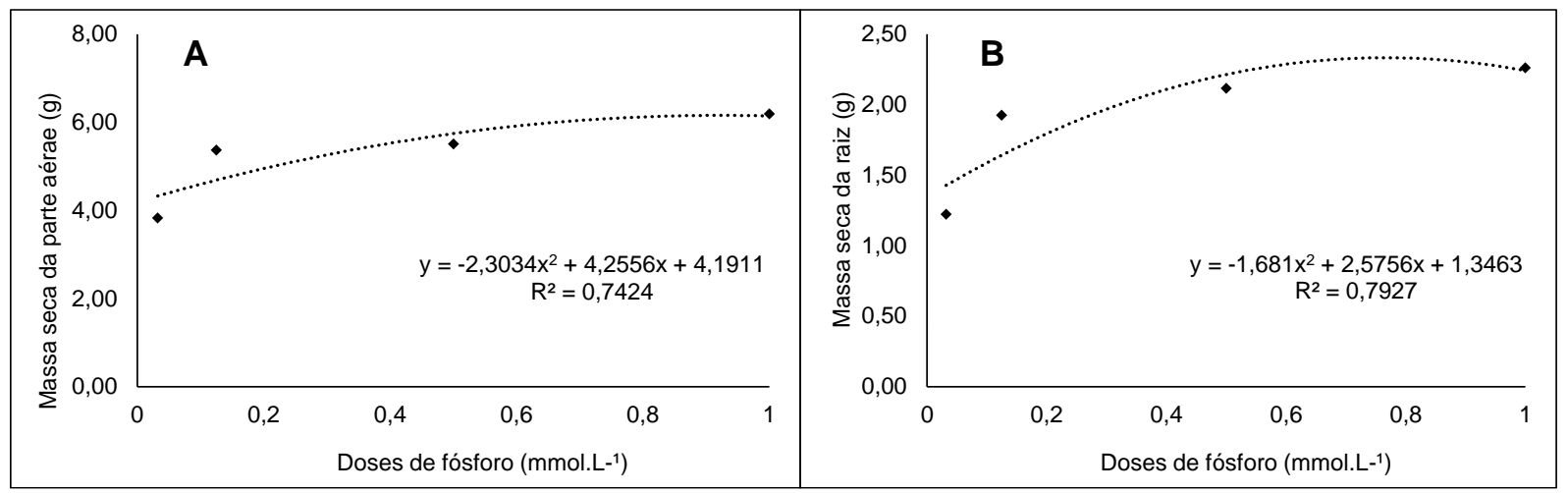

Fonte: Autores. 
A relação entre massa seca de parte aérea e massa seca da raiz foi ajustada no modelo quadrático e o ponto de mínimo foi calculado em 2,57 na dose 0,628 mmol.L $\mathrm{L}^{-1}$ (Fig. 9). Nessa dose, em comparação as demais, é possível observar o maior incremento da massa seca de raiz em relação a parte aérea. Quaresma, Pacheco, Silva, e Batista (2020), trabalhando com substratos para mudas de maracujá amarelo em casa de vegetação, observaram que o uso do adubo NPK (280; 480; 350 mg.dm-3) aumentou a relação massa seca de parte aérea e raiz. A distribuição dos assimilados na planta entre a parte que transpira e parte que absorve água, é visualizada através da relação entre massa seca da parte aérea e massa seca de raiz (Almeida, Mayrinck, Zanini, Dias, \& Baroni, 2014).

Figura 9. Relação da produção de massa seca da parte aérea e da raiz de mudas de maracujazeiro, em função das concentrações de fósforo na solução nutritiva, 47 dias após a semeadura.

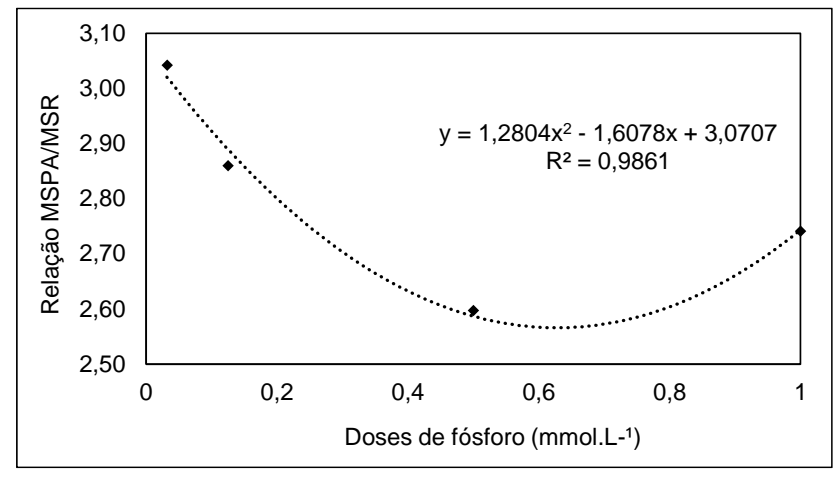

Fonte: Autores.

Houve diferença significativa para o volume de raiz das plantas em função das doses de fósforo. Verificou-se que as plantas atingiram o volume máximo de raiz de $43,13 \mathrm{~mL}$ na dose de $0,784 \mathrm{mmol} \cdot \mathrm{L}^{-1}$ (Figura 10). O estudo do volume de raiz é simples de ser realizado e fornece com precisão o espaço ocupado pela planta para a exploração de água e nutrientes. $\mathrm{Na}$ sequência, observam-se três autores com avalições de volume de raiz realizadas em mudas de maracujá amarelo aos 50 dias. Costa et al., (2018), utilizando a semeadura em sacos de polietileno, com diferentes substratos e ambientes de luz, obtiveram o valor máximo de 1,13 mL. Kato et al., (2018), trabalhando com adubação de NPK (14-14-14) de liberação lenta, em tubetes de $100 \mathrm{~mL}$, observaram volume máximo de $1,90 \mathrm{~mL}$ na dose $6,85 \mathrm{~g}, \mathrm{~L}^{-1}$. Barros et al., (2013), encontraram o maior valor de volume de raiz de $17 \mathrm{ml}$ no tratamento que continha solo + esterco bovino curtido. Os valores observados na literatura foram inferiores ao observados no trabalho, indicando que a pesquisa em solução nutritiva é promissora para uma boa formação do sistema radicular em mudas de maracujá azedo.

Figura 10. Volume de raiz de mudas de maracujá azedo, em função das concentrações de fósforo na solução nutritiva, 47 dias após a semeadura.

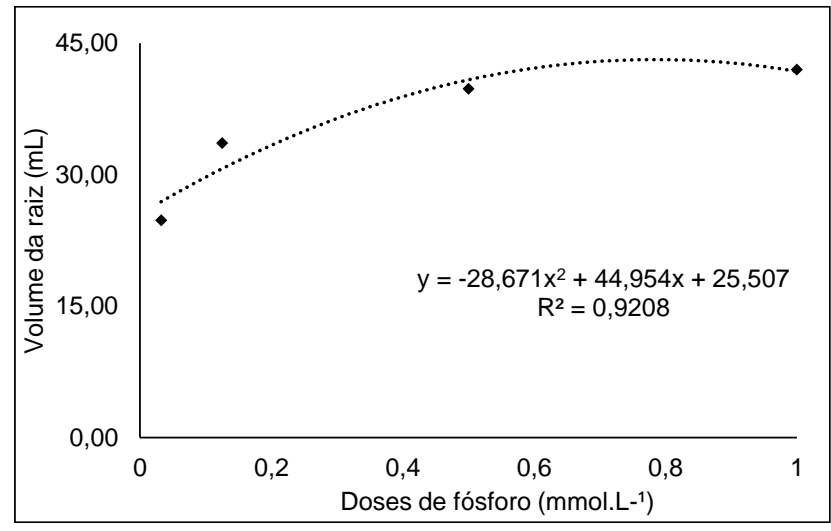

Fonte: Autores. 
O maior valor para IQD de 0,816 foi observado na dose de 0,784 mmol. $\mathrm{L}^{-1}$, mostrando uma menor necessidade do fósforo em relação a solução padrão de $1 \mathrm{mmol} \cdot \mathrm{L}^{-1}$, mas mantendo a qualidade exigida em campo (Figura 11). Em um plantio definitivo, o uso de mudas de qualidade é de extrema importância para o sucesso da cultura empregada. Essa qualidade pode ser medida através de atributos morfológicos ou simplesmente por sua visualização (Fonseca, Valéri, Miglioranza, Fonseca, \& Couto, 2002). O Índice de Qualidade de Dickson (IQD), conforme mostrado por Smiderle, Silva, Souza, e Souza (2017), apresenta uma forte correlação positiva com a massa seca da raiz e da parte aérea, demonstrando que essas variáveis são linearmente proporcionais ao índice. Por essa razão, o IQD indica a robustez das mudas, sendo considerado um bom indicador de qualidade.

A qualidade de mudas é normalmente atribuída em viveiros comerciais em função de um bom desenvolvimento do diâmetro de colo, espesso e rígido, uniformidade entre mudas, boa formação de parte aérea, vigor, ausência de sintomas de deficiência nutricional; sanidade e sistema radicular integro (Barbosa, Parajara, Barbosa, \& Barbosa, 2014). De acordo com Fonseca et al., (2002), a escolha de mudas de qualidade com base em apenas em parâmetros morfológicos pode ser arriscada, indicando o IQD como um bom índice para se determinar a qualidade das mudas.

Em trabalho realizado por COSTA et al., (2018), utilizando diferentes substratos e ambientes na produção de mudas de maracujazeiro amarelo em sacos de polietileno, foram obtidos valores de IQD máximo de 0,24. Porém, Almeida, Barros, Silva, Procópio, e Mendonça (2011), também testando diferentes substratos na produção de mudas de maracujá amarelo em bandejas, obtiveram maior IQD nos tratamentos S4 (50\% solo + 50\% esterco bovino) e S5 (50\% solo + 50\% esterco caprino), com os valores de 1,18 e 1,48 , respectivamente.

Figura 11. Índice de Qualidade de Dickson (IQD) de mudas de maracujazeiro, em função das concentrações de fósforo na solução nutritiva, 47 dias após a semeadura.

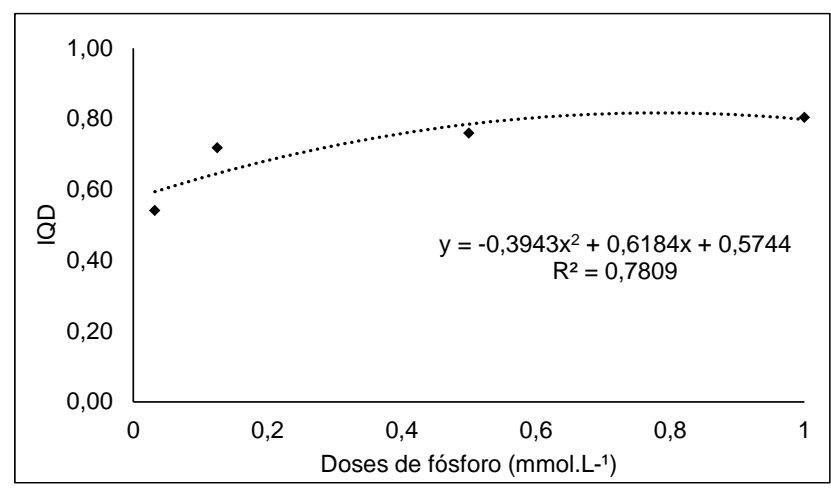

Fonte: Autores.

O Índice de Qualidade de Dickson (IQD) é um indicador importante na avaliação das mudas por considerar as características biométricas da planta. Porém, sua análise fica restrita e condicionada aos tratamentos específicos de um experimento, sendo relativa sua comparação com a literatura. Assim, entre os valores obtidos pelos tratamentos aplicados em um estudo, considera-se melhor o maior valor de IQD obtido.

A eficiência de absorção e a eficiência de translocação de fósforo apresentaram efeito quadrático positivo. Por outro lado, a eficiência de utilização apresentou efeito quadrático negativo na regressão (Figura 12). O ponto de máxima absorção de fósforo foi estimado em 22,18 (mg. $\left.\mathrm{g}^{-1}\right)$ na dose de $0,685 \mathrm{mmol} \cdot \mathrm{L}^{-1}$. A maior eficiência de translocação foi estimada na dose de $0,593 \mathrm{mmol} \cdot \mathrm{L}^{-1}$ como o valor de 0,213 . O ponto de menor eficiência de utilização foi observado no ponto de mínimo da regressão, que foi alcançado na dose de $0,683 \mathrm{mmol} \cdot \mathrm{L}^{-1}$, com valor de $1,09\left(\mathrm{~g}^{2} \mathrm{mg}^{-1}\right)$.

Observou-se nos gráficos das Figuras 9 e 12 (A, B) que o aumento do fornecimento de fósforo proporcionou um 
aumento da absorção e translocação do elemento para a parte aérea, atingindo seus pontos de máximo próximo ao ponto de maior equilíbrio da relação de crescimento entre raízes e parte aérea. Esses resultados demonstram que a planta possui uma capacidade de regular a quantidade máxima de nutriente absorvida (Abichequer \& Bohnen, 1998).

Os resultados obtidos com as curvas de eficiência de absorção e translocação são inversos à resposta observada na curva obtida para a eficiência de utilização. A eficiência de utilização é maior quando se tem as menores concentrações de fósforo na solução nutritiva. Com a dose de fósforo de $0.032 \mathrm{mmol} . \mathrm{L}^{-1}$ observa-se o valor de $2,40 \mathrm{~g}^{2} \mathrm{mg}^{-1}$. Depois a eficiência decresce com o aumento da concentração do nutriente até atingir o seu valor mínimo de $1,09 \mathrm{~g}^{2} \mathrm{mg}^{-1}$, o que corresponde a concentração de fósforo de $0.683 \mathrm{mmol} \cdot \mathrm{L}^{-1}$. Após esse limite mínimo, é possível observar um aumento da eficiência de utilização com o aumento da concentração (Fig. 12C). Quando o fósforo limita o crescimento vegetal, as raízes transformam-se em fortes drenos de carboidratos, causando maior limitação ao crescimento da parte aérea do que da raiz (Serra et al., 2012), o que aumenta a razão entre massa de raiz e parte aérea (Araújo e Machado, 2006). Entretanto, para a produção de mudas de maracujá azedo foi observado comportamento oposto. Observou-se que em baixas concentrações de fósforo ocorreu maior crescimento da massa seca da parte aérea em relação a da raiz (Fig. 9), assim como, observou-se também maiores eficiências de utilização do nutriente pelas mudas de maracujá (Figura 12C), o que representa uma característica adaptativa da planta à escassez do nutriente em sua fase inicial de crescimento. Os maiores valores observados para a eficiência de utilização representam melhor administração na alocação do nutriente para a massa seca total em relação ao conteúdo do nutriente na planta. 
Figura 12. Eficiência de absorção (A), translocação (B) e de utilização (C) de mudas de maracujazeiro, em função das concentrações de fósforo na solução nutritiva, 47 dias após a semeadura.

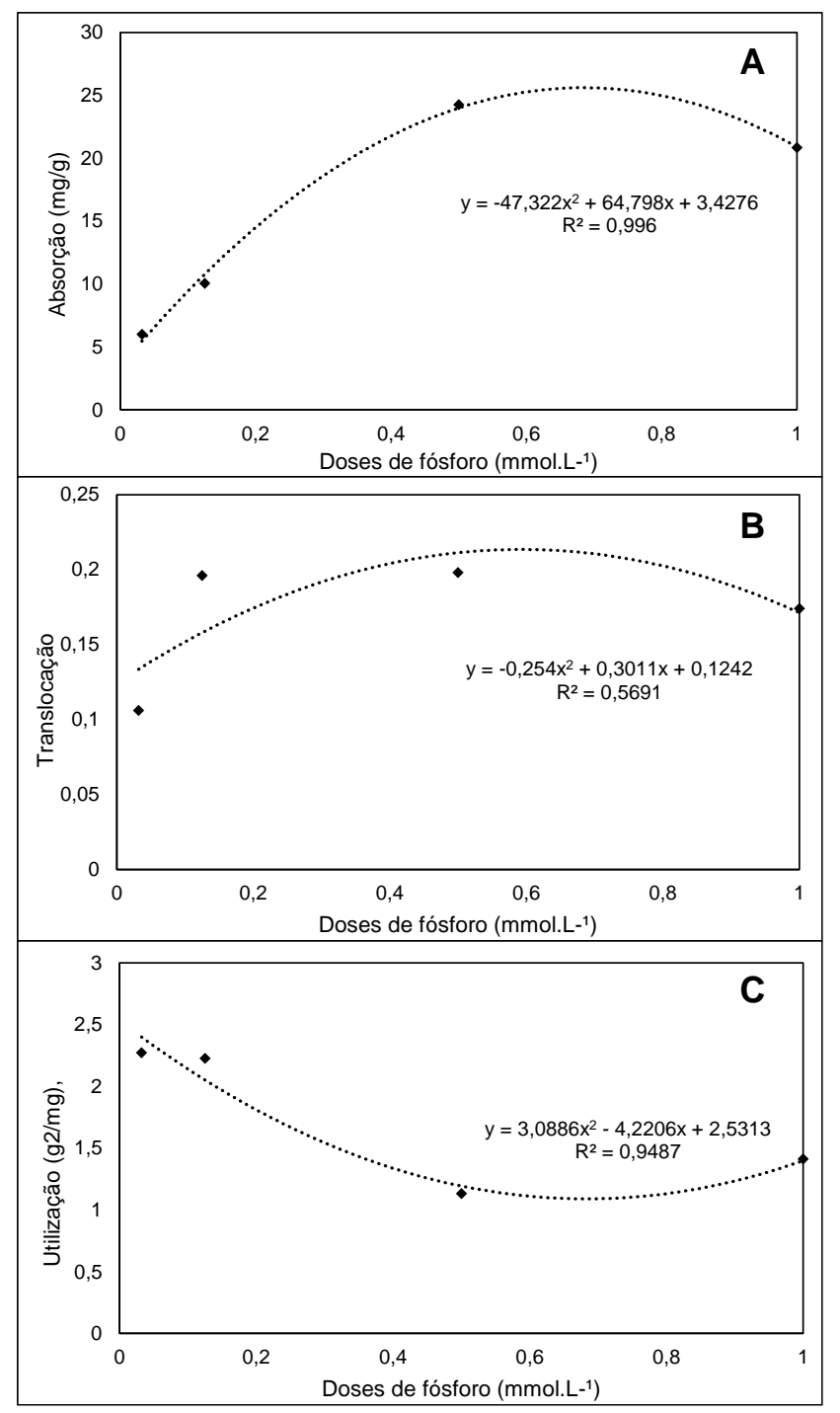

Fonte: Autores.

Considerando a concentração de 0,784 mmol.L-1 obtida para o melhor IQD e substituindo esse valor pelo " $\mathrm{x}$ " nas equações da Figura 12, observaram-se eficiências relativas de absorção e translocação de 98,17\% e 95,65\%, respectivamente. Referindo-se a eficiência de utilização, foi possível elevá-la em 2,88\% em relação ao seu ponto de mínima. Assim, esse raciocínio permite quantificar, com maior acurácia, a nutrição das mudas em relação ao fósforo. As plantas têm uma capacidade limitada para a absorção seletiva daqueles elementos que são essenciais para o seu crescimento. Além disso, elas absorvem elementos que não são necessários e podem até ser tóxicos (Marschner, 2012). A pesquisa realizada com solução nutritiva forneceu todos os nutrientes essenciais para o crescimento e desenvolvimento das mudas, em concentrações adequadas e sem possibilidade de toxidez, alcançando resultados promissores. Em continuidade às pesquisas, recomendamos a avaliação das mudas no cultivo tradicional em campo.

\section{Conclusão}

A produção de mudas de maracujá azedo por sementes obteve bons resultados no cultivo hidropônico, podendo se tornar uma alternativa para a produção de mudas comerciais. 
Considerando o objetivo de qualidade das mudas de maracujá azedo, o uso de $0,784 \mathrm{mmol} . \mathrm{L}^{-1}$ de fósforo em solução nutritiva, proporcionou o maior valor para índice de qualidade de Dickson. Essa concentração permitiu alcançar eficiências relativas de absorção e translocação de $98,17 \%$ e 95,65\%, respectivamente, além de superar em 2,88\% a eficiência de utilização em relação ao seu ponto de mínima.

O uso da concentração de fósforo de 0,784 mmol. $\mathrm{L}^{-1}$ proporcionou uma economia de cerca de $22 \%$ do nutriente em relação ao valor original da concentração utilizada na solução nutritiva.

Sugerimos como trabalho futuro o teste das mudas em campo utilizando o método tradicional de produção de mudas e o método em hidroponia.

\section{Agradecimentos}

Agradeço a Universidade Federal do Espírito Santo pelo apoio e a CAPES pelo fornecimento da Bolsa de pesquisa.

\section{Referências}

Abichequer, A. D., \& Bohnen, H. (1998). Eficiência de absorção, translocação e utilização de fósforo por variedades de trigo. Revista Brasileira de Ciência do Solo, 22(1), pp. 21-26.

Aguiar, A. T. E., Gonçalves, C., Paterniani, M. E. A. G. Z., Tucci, M. L. S., \& Castro, C. E. F. de. (2014). Instruções Agrícolas para as Principais Culturas Econômicas (7a. ed.), Boletim IAC, No. 200. pp. 452. Instituto Agronômico.

Almeida, J. P. N. de, Barros, G. L., Silva, G. B. P. da, Procópio, I. J. S., \& Mendonça, V. (2011). Substratos alternativos na produção de mudas de maracujazeiro amarelo em bandeja. Revista GVAA, 6(1), 188-195.

Almeida, R. S., Mayrinck, R. C., Zanini, A. M., Dias, B. A. S., \& Baroni, G. de R. (2014). Crescimento e qualidade de mudas de Croton floribundus spreng. em diferentes recipientes e substratos. Enciclopédia Biosfera, 10(19), 672-685.

Alvares, C. A., Stape, J. L., Sentelhas, P. C., Gonçalves, J. L. de M., \& Sparovek, G. (2013). Köppen's climate classification map for Brazil. Meteorologische Zeitschrif, 22(6), 711-728.

Araújo, A. P. \& Machado, C. T. de T. (2006). Fósforo. In: Fernandes, M. S. Nutrição mineral de plantas. (pp. 253-280). Sociedade Brasileira de Ciência do Solo.

Barbosa, L. M., Parajara, F. C., Barbosa, K. C., \& Barbosa, T. C. (2014). Manual de orientação para implantação de viveiro de mudas.

Barros, C. M. B., Müller, M. M. L., Botelho, R. V., Michalovicz, L., Vicensi, M., \& Nascimento, R. do. (2013). Substratos com compostos de adubos verdes e biofertilizante via foliar na formação de mudas de maracujazeiro-amarelo. Semina: Ciências Agrárias, 34(6), $2575-2588$.

Brasil. Ministério da Agricultura e Reforma Agrária. (2009). Regras para análise de sementes.

Brasil, E.C., Viégas, I. de J. M., Silva, E. S. A., \& Gato, R. F. (1999). Nutrição e adubação: conceitos e aplicações na formação de mudas de pimenta longa (Documentos, No. 13, pp. 23). Belém: Embrapa Amazônia Oriental.

Costa, F. M., Anjos, G. L. dos, Camilo, G. B. da M., Oliveira, U. C. de, Souza, G. S. de, \& Santos, A. R. dos. (2018). Produção de mudas de maracujazeiro amarelo em diferentes composições de substrato e ambiente. Revista de Ciências Agrárias. 41(1), 138-146.

Dickson, A., Leaf, A. L., \& Hosner, J. F. (1960). Quality appraisal of white spruce and white pine seedling stock in nurseries. Forest Chronicle, $36(1), 10^{-1} 3$.

Faleiro, F. G., \& Junqueira, N. T. V. (2016). Maracujá: o produtor pergunta, a Embrapa responde. Brasília, DF: Embrapa.

Ferreira, E. B., Cavalcanti, P. P., \& Nogueira, D. A. (2017). Package 'ExpDes.pt': Experimental Designs Package (Portuguese). Disponível em: $<$ https://cran.r-project.org/web/packages/ExpDes.pt/ExpDes.pt.pdf $>$.

Fonseca, E.P., Valéri, S.V., Miglioranza, É., Fonseca, N.A.N., \& Couto, L. (2002). Padrão de qualidade de mudas de Trema micrantha (L.) Blume, produzidas sob diferentes períodos de sombreamento. Revista Árvore, 26(4), 515-523.

Furtini, A. E., Neto. Vale, F. R. do, Resende, A. V. de, Guilherme, L. R. G., \& Guedes, G. A. de A. (2001). Fertilidade do solo (Curso de pós-graduação "Lato Sensu" a Distância - Fertilidade do Solo e Nutrição de Plantas no Agronegócio, 261). Lavras: UFLA/FAEPE.

Gontijo, G. M. (2017). Cultivo do Maracujá: informações básicas (Coleção Emater, No. 26, pp. 40). Brasília: Emater-DF.

Instituto Brasileiro de Geografia e Estatística (IBGE). (2020). Maracujá: área plantada e quantidade produzida. Brasília, 2018. (Produção Agrícola Municipal, 2017). <http://www.sidra.ibge.gov.br>.

Kato, D. S., Silva, C. M. da, Higuchi, M. T., Bauchrowitz, I. M., Santos, J. dos, Neto. Shimizu, G. D. \& Oliveira, A. F. de. (2018). Produção de mudas de maracujá amarelo submetidas a doses crescentes de adubação de liberação lenta. Rev. Terra \& Cult, 34, 11. 
Li, B., McKeand, S. E., \& Allen, H. L. (1991). Genetic variation in nitrogen use efficiency of loblolly pine seedlings. Forest Science, 37(2), pp. 613-626.

Lima, A. de A., Caldas, R. C., \& Santos, V. da S. (2006). Germinação e crescimento de espécies de maracujá. Revista Brasileira de Fruticultura, 28(1), pp. $125-127$.

Maguire, J. D. (1962). Speed germination-aid in selection and evaluation for seedling emergence and vigor. Crop Science, 2(2), 176-177.

Malavolta, E. (2006). Manual de Nutrição Mineral de Plantas. Agronômica Ceres.

Manica, I. M., Brancher, A., Sanzonowicz, C., Icuma, I. M., Aguiar, J. L. P. de, Azevedo, J. A. de, Vasconcellos, M. A. da S., \& Junqueira, N. T. V. (2005). Maracujá-doce: Tecnologia de produção, pós-colheita, mercado. Cinco Continentes.

Marschner, H. (2012). Mineral nutrition of higher plant. (3a. Ed., pp. 651). Academic Press.

Martinez, H. E. P., \& Silva, J. B. da, Filho. (2012). Introdução ao cultivo hidropônico de plantas (3a. ed.), 111. ED. UFV.

Morgado, M. A. D., Bruckner, C. H., Rosado, L. D. S., Assunção, W., \& Santos, C. E. M. dos. (2013). Estimação da área foliar por método não destrutivo, utilizando medidas lineares das folhas de espécies de Passiflora. Revista Ceres, 60(5), 662-667.

Negreiros, J. R. da S., Álvares, V. de S., Braga, L. R., \& Bruckner, C. H. (2004). Diferentes substratos na formação de mudas de maracujazeiro-amarelo. Revista Ceres, 51(294), 243-345.

Nogueira, G. C., Filho. Roncatto, G., Ruggiero, C., Oliveira, J. C. de, \& Malheiros, E. B. (2010). Desenvolvimento de plantas de maracujazeiro-amarelo produzidas por enxertia hipocotiledonar em cinco porta-enxertos de passifloras silvestres. Revista Brasileira de Fruticultura, 32(2), 527-534.

Pimentel-Gomes, F. (2009). Curso de estatística experimental (15a. ed.), 451. Fealq.

Prado, R. de M., Vale, D. W. do, \& Romualdo, L. M. (2005). Fósforo na nutrição e produção de mudas de maracujazeiro. Acta Scientiarum Agronomy, 27(3) 493-498.

Primavesi, A. C. P. A., \& Malavolta, E. (1980). Estudos sobre a nutrição mineral do maracujá amarelo: VIII. Extração de nutrientes e exigências nutricionais para o desenvolvimento vegetativo. An. Esc. Super. Agric. Luiz de Queiroz, 37(2), 603-607.

Quaresma, J. P.; Pacheco, D. D.; Silva, T. C. \& Batista, C. H. (2020). Produção de mudas de maracujazeiro amarelo (Passiflora edulis Sims f. flavicarpa) em resposta a calagem, NPK e micronutrientes. Research, Society and Development. 9(8), 1-25.

R Core Team. (2019). R: A language and environment for statistical computing. R Foundation fot Statistical Computing, Vienna, Austria. https://www.Rproject.org/.

Santos, A. N., Soares, T. M., Silva, E. F. F., Silva, D. J. R., \& Montenegro, A. A. A. (2010). Cultivo hidropônico de alface com água salobra subterrânea e rejeito da dessalinização em Ibimirim, PE. Revista Brasileira de Engenharia Agrícola e Ambiental, 14(9), 961-969.

Santos, C. C., Motta, I. de S., Carneiro, L. F., Santos, M. C. S., Padovan, M. P., \& Mariani, A. (2014). Produção Agroecológica de Mudas de Maracujá em Substratos a Base de Húmus de Minhoca e Casca de Arroz Carbonizada. Cadernos de Agroecologia, 9(4), 1-10.

Serra, A. P., Marchetti, M. E., Vieira, M. C., Robaina, A. D., Nascimento, J. M., Veronesi, C., \& Matos, F. (2012). Eficiência da absorção, translocação e uso de N e P pela Pfaffia glomerata (Spreng.) Pedersen. Rev. Bras. PI. Med., 14(2), 255-260.

Siddiqi, M., \& Glass, A. D. M. (1981). Utilization index: a modified approach to the estimation and comparison of nutriente utilization efficiency in plant. Journal od Plant Nutrition, 4, 289-302.

Silva, F. C. da, Santos, A. D. dos, Coscione, A. R., Vitti, A. C., Boaretto, A. E., \& Barreto, W. de O. (2009). Manual de análises químicas de solos, plantas e fertilizantes (2a. ed.), 627. Embrapa Informação Tecnológica; Rio de Janeiro: Embrapa Solos.

Silva, M. R. R. da, Ignacio, L. A. P., \& Silva, G. A. da. (2017). Desenvolvimento de mudas de maracujá amarelo em função de diferentes doses fósforo reativo. Revista de Agronegócio, 6(1), 41-50.

Smiderle, O. J., Silva, T. de J. da, Souza, A. A. de, \& Souza, A. das G. (2017). Correlação morfológica da qualidade de mudas de maracujazeiroamarelo com substratos alternativos. Revista Congrega.

Swiader, J. M., Chyan, Y., \& Freiji, F. G. (1994). Genotypic diferences in nitrate uptake and utilization efficiency in pumpkin hybrids. Journal of Plant Nutrition, 17(10), 1687-1699.

Taiz, L., \& Zeiger, E. (2017). Fisiologia vegetal (6a. ed.), 627. Artmed.

Torchelsen, M. de M. (2013). Produção de mudas por estaquia e cultivo protegido de maracujazeiro-amarelo (Dissertação de Mestrado). Universidade Federal de Pelotas, Pelotas, Brasil. 